\title{
Practical Dilemma Faced by Cooperative Governance in Urban Communities
}

\author{
$\mathrm{Mu} \mathrm{Wei}$ \\ School of Public Management (SPM), \\ Yunnan University of Finance and Economics,P. R. China \\ (weimuzsu@163.com)
}

\begin{abstract}
With the rising of governance theory, Chinese scholars began to analyze the urban community governance models from the perspective of the governance theory,especially the cooperative governance theory. The research outlined the theoretical framework and the consensus of cooperation govern- ance theory through the investigation of existing literature.It also combined the experiences of community governance to rethink the applicability of the governance theory. The research found that there were cooperative behaviors in community governance,but because of the agent's self interest logic, the diffusion of community publicity and the division of responsibilities in com- munity governance, the urban community cannot achieve the real cooperative governance. Therefore,to analyze current urban community cooperative action, scholars have to take the commu- nity nature into consideration.Besides, the will of agents, the governance ability and the development of community governance network should all be completely testified.
\end{abstract}

Keywords-urban communities; cooperative govern-ance in communities; practical dilemma; applicability

\section{INTRODUCTION}

Social changes with market economy as the orientation have accelerated the integration of resources and structural transformation in grassroots society. Since the 1990s, with the rapid advancement of housing privatization and marketization, commercial housing communities have replaced unit residences as the main form of urban living. Changes in the form of residence have brought new subjects in community governance, e.g. property management companies and owner committees, who are also gradually playing an important role in the public life of urban communities. The new pattern where multiple subjects participate in shaping urban community governance has aroused widespread concern in the academic community.

In the context of post-Fordism and globalization, the welfare states urgently need to be reconstructed. After the "market failure" and "government failure", people hope that the third sectors could play an important role in supplying public goods and allocating social resources. Consequently, the cooperative governance theory came into being. The cooperative governance theory that originated in the Western society has aroused great interest among Chinese scholars who have continuously expanded the application scope of this theory and strengthened efforts in interpreting this theory from the perspective of different disciplines. Besides, on this basis, they analyze the international relations implied by the governance of international affairs, the intergovernmental relations within the state power of a country as well as the public-private partnerships between government sectors and social organizations, further deepening discussions on grassroots democracy by explaining the operation mechanism of public affairs. The broadness of the concept of cooperative governance has led to inclusiveness in the scope of interpretation. Combined with the complex attributes of Chinese urban communities, the cooperative governance theory helps to reflect the governance patterns of urban communities in China[1].

The second reason is that the main subjects in community governance are not competent enough to reach a consensus and thereby cannot cooperate smoothly. The subjects in the self-governance network lack sufficient social power, and the problem of excessive power may arise especially when they interact with the owner committee and the property management company, thus it is difficult for community public space to truly develop[2]. It is hard to establish a cooperation platform in the community governance structure driven by the "troika", i.e. the owner committee, the property management company and the neighborhood committee. Consequently, not only are there frequent disputes between the owner committee and the property management company, but the rights protection actions of the owner committee have also brought about great troubles to the neighborhood committee, there are even fierce frictions between the two sometimes[3]. Without community identity, each subject participating in community governance goes his own way, which is also one of the reasons why it is difficult to form overall cooperation in community governance. Because of the "community dilemma" in grassroots social governance in urban communities featuring the serious insufficiency of residents' social identification and participation in community governance, the diversified cooperation governance structure in urban communities often becomes a mere formality, and returning to the construction of community publicity will be a key variable to promote community cooperation governance[4]. Social organizations, public space and community elites play an important role in the construction of the public spirit. Likewise, the creation of community public spirit cannot go without the general participation of the residents either.

\section{CONNOTATION AND APPLICATION OF THE COOPERATIVE}

\section{GOVERNANCE THEORY}

When the cooperative governance theory emerged at the very beginning, it had a huge impact on public management, and was rapidly applied to many social 
science research fields. Meanwhile, there were also many scholars who chose the research orientation of criticizing constructivism by reflecting on the applicability and theoretical limits of the cooperative governance theory from different angles. At present, there is still controversy over the definition of the cooperative governance theory in the academic world. To clarify the connotation of the cooperative governance theory is the precondition to apply the cooperative governance theory. The paper will summarize and analyze relevant research results of cooperative governance in communities.

\section{A. Connotation of the Cooperative Governance Theory}

Roots, a representative of the governance theory, believes that governance is a kind of "self-organized network", and the basic characteristics of governance include interdependence between organizations, ongoing interaction between network members when exchanging resources and negotiating common purposes; confidence-based interaction adjusted by the rules negotiated and agreed by network participants; a considerable degree of autonomy relative to the state maintained [5]. By reviewing the concepts of governance proposed by scholars from various countries, Stoke put forward the following five viewpoints: Governance refers to social public institutions and actors from the government but not limited to the government; the governance theory recognizes boundaries between public and private sectors and the ambiguity of their respective responsibilities; governance clearly affirms the existence of power dependence among various social public institutions that involve collective behaviors; governance refers to self-governance of the actor's network, but the possibility of "bringing back the national governance" if necessary is not excluded either; governance means that the ability to get things done is not limited to the government's power, nor is it limited to the government's commanding orders or use of authority [6]. Based on the background of the era and the realistic foundation, when the governance theory just rose, governance mainly refers to win-win cooperation between the government and social organizations in the supply of public goods. The government and social public organizations are the main subjects in cooperation. In ideal cases, the autonomy of public organizations and state intervention can form two forces well-matched in strength. As far as the relationship between the two parties is concerned, the cooperative relationship between public and private actors is interdependent. Due to the participation of multiple subjects, all the actors have to conduct continuous coordination and interaction. The multiple correlation coefficients in the operation of the relationship make the results even more uncertain.

\section{B. Application of the Cooperative Governance Theory}

Whether as a new public management theory or an ideal social model, the cooperative governance theory has aroused widespread concern in the social academic circle. The cooperative governance theory originated in the western society during the late 20th century, the specific historical background has not only shaped the theoretical mission of cooperative governance, but also determined the adaptability and theoretical limits of the cooperative governance theory. Combined with the background of the post-industrial era and the development degree of the civil society, the development stage and the social structure of China are fundamentally different from those of Western countries, which determines that in the process of applying the cooperative governance theory, China must face up to the social status and important role of government sectors. The coupling degree of the cooperative service system between government sectors and social organizations will directly restrict the application degree of cooperative governance.

\section{PRACTICAL Dilemma AND TheORETICAL REFLECTION}

\section{OF COOPERATIVE GOVERNANCE IN COMMUNITIES}

\section{A. Cause Analysis of Dilemma Faced by Cooperative}

\section{Governance in Communities}

The self-interest logic of the main subjects involved in community governance means that each governance subject tries to strive for their own interests. Even if cooperation is achieved and the interests of the community as a whole are realized, yet it is still based on each subject's original intention of pursuing their own interests. From an overall point of view, the owner committee negotiates with the property management company about the property fees and public expenditures to protect basic rights and interests of the owners, and their cooperation in public construction can promote the construction of the community and meet the needs of the owners in terms of public life. Unable to tackle the property disputes, the property management company resorts to the neighborhood committee, which can resolve grassroots conflicts and stabilize social order. Rich cultural activities are conducive to improving residents' satisfaction. However, besides the superficial phenomena, the interest appeals and values behind each subject cannot be ignored.

\section{B. Reflection of Cooperative Governance in Communities}

The essence of collaborative logic is the individualistic behavior of instrumental rationality, while the cooperative logic is the moral behavior of practical rationality. In cooperation at the highest level, each subject pursues an integral goal that transcends individual interests and internally coordinates the division of labor under based on a consistent overall goal, with responsibility and risk shared. The current community cooperation is a low-level collaborative behavior. In other words, subjects involved in community governance analyze the cooperative behavior based on their respective interests, expecting to gain some returns. Agreement reached in the aspect of interest is more like simple exchange logic rather than cooperative and reciprocal logic. Excluding the standpoint of moral values, community collaboration does not regard morality as the basic and decisive value for cooperation. It is precisely because of the absence of moral foundation that it is difficult to form a universal consensus in community cooperation. Nor can a stable cooperation network be established. Therefore, the collaborative behavior is sometimes accidental, and the collaborative relationship is loose and easily broken. So, the neighborhood committee, the owner committee and the property management company find it hard to form cooperative governance to achieve long-term goals of community construction[7].

\section{CONCLUSION}

Cooperative governance is of great theoretical value

for rethinking the governance structure of urban communities and advancing the effects of urban community governance. Based on the current development 
status of urban community governance and the practice of cooperative governance in communities, it is necessary to define the applicability of the cooperative governance theory. Currently, cooperation is urgently needed in community governance, and certain cooperative behaviors have emerged. For example, the owner committee and the property management company cooperate to organize public construction, and the neighborhood committee and the property management company cooperate to get prepared for inspections and jointly handle property disputes. However, cooperative governance in communities still faces dilemmas which are mainly manifested as the low level of community cooperative behavior, rationalization of the tools of community cooperation logic and the non-subjectivity of community cooperation network. The urban society is a society of strangers. In urban communities, publicity is often diffused, the owners' sense of community is usually weak, various governance organizations lack a strong sense of being subjects involved in community governance, and each governance subject follows the self-interest logic and avoids responsibility and risk, leading to division of responsibilities in the community cooperation space. Cooperative governance in communities is therefore difficult to achieve.

\section{REFERENCES:}

[1] Chen Jiaxi. Reflection on Governance Structure of Urban Communities in China[J]. Wuhan University Journal (Philosophy \& Social Sciences), 2015(1):71 - 76

[2] Xiao Lin. Asymmetrical Legitimacy: Comparison of the Neighborhood Committee and the Owner Committee[J]. Sociology Review of China, 2014(6): 58 - 68

[3] Zhang Zhenyang, Wang Zhe. Cooperative Governance with Leadership: Cooperative Community Governance with Chinese Characteristics and Its Transformation: A Case Study of Comprehensive Environment Improvement Work of G Community in Shanghai[J]. Socialism Studies, 2016 (1): $75-84$

[4] Wang Hansheng, Wu Ying. The "Visible" and "Invisible" State in Grassroots Society[J]. Socialism Studies, 2011( 1): $63-95$

[5] Xiao Lin. The Building of State Penetration Capacity: State's Responsive Tactics Under the Challenge of Community Governance[J]. Journal of Harbin Institute of Technology (Social Sciences Edition), 2013(6): $11-17$

[6] Zhang Lei, Liu Limin. Property Management as a New Public Space: the Tension between an Over-powered State and an Underprivileged Society in China[J]. Society, 2005( 1): $144-163$

[7] He Pingli. Confliction, Predicament and Introspection: The Basic Body of Community Administration and the Construction of Civil Society[J]. Journal of Shanghai University (Social Sciences Edition), 2009(4) : 20 $-31$ 